\title{
Developing perspectives on 'the demonstration' as a signature pedagogy in design and technology education
}

\author{
Matt McLain $^{1}$ (D)
}

Accepted: 27 August 2019 / Published online: 4 September 2019

(c) The Author(s) 2019

\begin{abstract}
This paper builds on a previous study of the 'demonstration' as a signature pedagogy in design and technology (D\&T). The demonstration is a fundamental pedagogical tool in practical subjects, for the development of learners' procedural knowledge, from observation and imitation to autonomy and adaption of a technique. As such, it tends to align itself at the restrictive end of an expansive-restrictive pedagogical continuum. In the preceding study, a dialogue emerged around the role of the teacher as a "competent management of the learning experience", including teachers' competency and clarity of subject knowledge. The findings of this study highlight two similar, yet distinct, perspectives of the teacher as an expert and the teacher as a facilitator. This study continues a developing professional conversation around the nature of the demonstration, exploring a snapshot of teacher educators' subjective beliefs and values. The responses of the participants to a set of 62 statements, representing a range of potential opinions and perspectives, were deployed and analysed using Q Methodology. The sample is purposive and comprised of D\&T teacher educators based in England. The study draws parallels with direct instruction and demonstration, and concludes that there different approaches to and ways of viewing demonstration. In addition, further consideration of the expansive-restrictive continuum as a framework for planning and evaluating learning in D\&T may support theorisation of the subject, inculcation of theory and research informed practice.
\end{abstract}

Keywords Demonstration · Teacher modelling · Design and technology · Initial teacher education $\cdot$ Teacher educator $\cdot \mathrm{Q}$ Methodology

\section{Introduction}

McLain (2016, 2017) and McLain et al. (2013, 2015) have postulated that 'the demonstration' is a signature pedagogy in design and technology (D\&T), but has received little attention in pedagogical and research literature. This was despite acknowledgement by Petrina that it was the "single most effective method for the technology teacher" (2007, p. 1).

Matt McLain

m.n.mclain@1jmu.ac.uk

1 Liverpool John Moores University, IM Marsh Campus, Barkhill Road, Liverpool L17 6BD, UK 
The research question for this study is-'What do D\&T teacher educators believe to be effective practice when demonstrating skills and knowledge?' This study continues to develop the dialogue, begun by McLain (2017) and McLain et al. (2015), around the subjective views on the 'demonstration' in D\&T; focusing on teacher educators in England and building on the initial analysis of data discussed in McLain (2016, 2017).

\section{Literature review}

McLain (2016, 2017) demonstration was described as encompassing aspects of teacher modelling and explaining, often supported by questioning. Furthermore, 'demonstration' typically focuses on practical techniques and procedures, often (although not exclusively) with regard to making and tool use. The literature review in McLain (2017) presented central concepts from a largely constructivist perspective and this paper seeks to critique different perspectives. This literature review explores the concept of a signature pedagogy and expands the discussion around the role of the 'demonstration' in relation to so-called domains of learning. In addition, literature from cognitive science (cognitive load theory, direct instruction and social learning theory), which purport to challenge the constructivist perspective on learning, is explored and evaluated.

\section{Signature pedagogy and 'the demonstration'}

The term signature pedagogy was first used by Shulman (2005) to describe the "types of teaching that organise the fundamental ways in which future practitioners are educated" (p. 52). Originally developed from the study of professional preparation, Shulman identified three fundamental dimensions of professional work-thinking, performing and acting with integrity - that receive varying weight across the professions. A signature pedagogy has a 'surface' structure consisting of pedagogical activities, such as a demonstration or design and make in D\&T. It also has a 'deep' structure that relates to bodies of knowledge and an 'implicit' structure comprised of the attitudes, values and dispositions. Despite the apparent distinctiveness of signature pedagogies between one discipline and another, Shulman points out that they may share common features; and the tried and tested principles identified as (domain specific) signature pedagogies may explain the effectiveness of these approaches over time. For example, the demonstration in D\&T may share similar features to direct instruction in other subjects, such as science (Milne and Otieno 2007) and physical education (Mosston and Ashworth 2002), as well as general descriptions from educational psychology (Martin 2016).

In a small-scale pilot study of seven teachers, McLain (2017) identified a variety of views on demonstration, which drew on general (pedagogic) and subject-specific (didactic) teacher knowledge. In response to the research question regarding teachers' beliefs about effective practice, the participants ranked competent subject knowledge as important-a commonly held view in education (e.g. DfE 2010, 2011; Shulman 1986)—underpinned by pedagogical knowledge and classroom management (McLain 2017).

The study correlated with Petrina's (2007) common components of a demonstration; in particular to the relevance and application of practical knowledge, which rely on the specialist knowledge of the teacher. However, Hattie (2009) cautions that without empathy for learners and verbal ability, subject knowledge alone potential limits the effectiveness of teaching to a "level of basic competence" (pp. 113-114)—both of which were implied 
in participants' responses in the pilot study. Therefore, it is important to see demonstration in a wider pedagogical context, requiring a complex interplay between subject and teacher knowledge-knowledge for teaching. The relationship and hierarchy of the teachers' beliefs was represented graphically (Fig. 1), indicating a higher value placed on restrictive (teacher led and focused on the development of specific knowledge and practice) over expansive (learner led and open-end activity with multiple potential outcomes) approaches, based on Fuller and Unwin's (2003) work on learning environments.

The restrictive-expansive framework, proposed by Fuller and Unwin, may be a useful tool for the D\&T community to consider when considering the intentions of a particular demonstration-or, indeed, when selecting pedagogical approaches in general. For example, a restrictive demonstration might focus on specific procedures that must be correctly followed to achieve a successful outcome, which would tend to result in learners' made outcomes appearing similar. Whereas, an expansive approach would provide stimulus for open-ended, design-oriented activity, leading to a range of outcomes. The responses to the pilot study indicated that participant views on demonstration favoured statements on the restrictive end of the continuum (i.e. competence with subject knowledge and skilful classroom management), rather than the expansive (i.e. consolidation of learning and facilitating of independence). Therefore, the demonstration alone may not be the most effective approach when the intention of teaching is to facilitate creativity and individual learner outcomes. Research from cognitive science, discussed below, supports the idea that direct instruction benefits some learners, particularly when learning new knowledge (Rowe 2006; Reynolds et al. 2014), whereas McLellan and Nicholl (2011) caution against restrictive approaches negatively influencing design thinking and creativity.

\section{'The demonstration' and domains of learning}

The popular taxonomy of educational objectives introduced by Bloom et al. (1956) identified three domains of learning: cognitive, affective and psychomotor. Bloom et al. initially defined the first, and most widely recognised, cognitive domain; updated by Andersen and

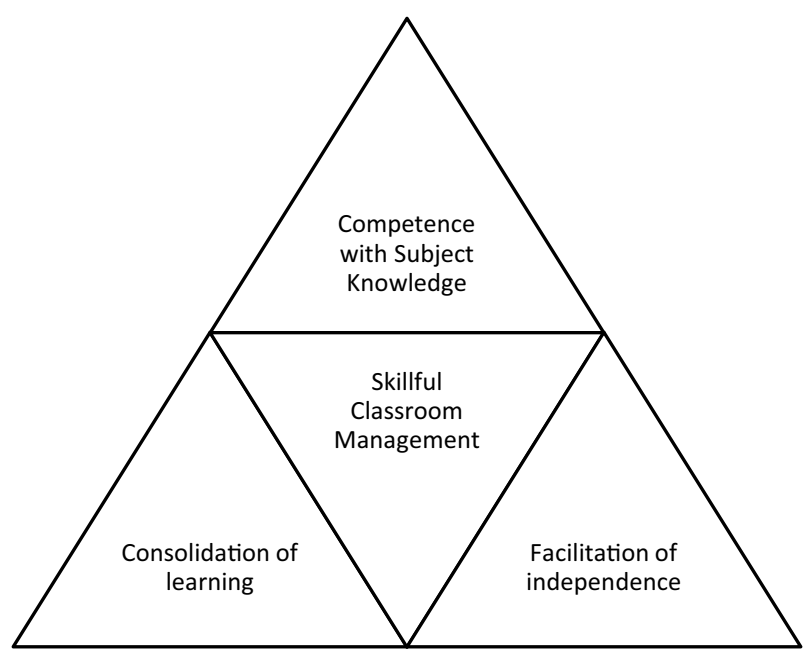

Fig. 1 Model of participant responses in McLain (2017) 
Krathwohl (2001), who were part of the original research team. Krathwohl et al. (1964) later developed the affective domain, which focuses on values and aspects of emotional intelligence. However, the team involved with the original study chose not to define the psychomotor domain. In fact, Simpson quotes Bloom as having found "so little done about [the psychomotor domain]", and "[did] not believe the development of a classification of these objectives would be very useful" at the time (Simpson 1972, p. 2, in Bloom et al. 1956, pp. 7-8). Simpson drew from expertise in practical subjects to describe a psychomotor domain (Table 1). The first four stages of Simpson's domain (perception to mechanism), align well with the definition of the demonstration, as outlined above. Dave (1967) had described a similar progression of skill to Simpson up to the level of mastery, with Dave's 'naturalisation' somewhat akin to Simpsons 'complex overt response' (Table 1).

Several other researchers have also sought to define the psychomotor domain (e.g. Harrow 1972) and redefine or update Blooms original work (Marranzo and Kendell 2007; Andersen and Krathwohl 2001). Marranzo and Kendell organise knowledge into three categories: information, mental procedures and psychomotor procedures, stating that all subject areas "can be described in terms of how much of these three types of knowledge" (p. 23) they are comprised of. They state that there is little specific psychomotor knowledge in geography, for example, whereas there is significant information and mental knowledge. Conversely, the D\&T curriculum could be argued to have relatively limited information (conceptual knowledge) that is solely its own. In England, for example, the National Curriculum programme of study (DfE 2013) and the General Certificate of Secondary Education (GCSE) (DfE 2015) subject content both refer to the application of knowledge from other disciplines, including computing, mathematics and science. Commenting on knowledge in D\&T, McCormick (1997) discusses the important and inextricable relationship between conceptual and procedural knowledge. Whilst "technology is geared to action" (p. 143), or the application of procedural knowledge, there is also an essential conceptual component. In other words, there may be distinct mental and psychomotor process in D\&T activities, such as designing and making, the two work hand in hand. Marranzo and Kendell propose that mental and psychomotor procedures follow similar patterns. Thus questioning the appropriateness of treating cognitive and psychomotor learning as inhabiting separate domains. However, the cognitive domain developed by Bloom differs from Dave and Simpsons approach, which recognise the role of the learner in observation and imitation. Furthermore, language utilised in these psychomotor domains is knowledge for (and of) action (Kimbell 2018; Kimbell et al. 1996), the pedagogy of transformation (Morrison-Love 2017) and the value of experience in the curriculum (Biesta 2014).

Table 1 Dave (1967) and Simpson's (1972) psychomotor domains

\begin{tabular}{ll}
\hline Dave (1967) & Simpson (1972) \\
\hline Imitation & Perception \\
& Set \\
Manipulation & Guided response \\
Precision & \\
Articulation & Mechanism \\
Naturalisation & Complex overt response \\
& Adaptation \\
& Origination \\
\hline
\end{tabular}


Whilst there may be value in applying learning objectives from a cognitive domain in practical education, the psychomotor domains may also help D\&T teachers to understand the demonstration, within a restrictive-expansive framework. For example, planning a demonstration aiming to develop novice learners' manipulation of tools or guided responses should differ to one aimed at more experienced learners, where the practical knowledge is naturalised with complex responses (Table 1). Furthermore, Simpson's adaption and origination require a pedagogical approach that expands rather than restricts learners' options. An implication is that a more expansive demonstration should focus less on process and more on choices; and for a learner to make confident choices, they should be able to drawn on knowledge developed through prior experience. The following sections explore the theories of cognitive load and social learning, as they apply to the teacher and learners through direct instruction; and how this may apply to pedagogical choices in a restrictive-expansive framework and demonstration in D\&T.

\section{The 'demonstration' and cognitive load theory}

Cognitive load theory postulates that novice learners freely exploring "a highly complex environment may generate a heavy working memory load that is detrimental to learning" (Kirschner et al. 2006, p. 80). This being attributed to limited or underdeveloped mental schemas, which are the mental representations of concept constructed by the learner. Kirschner, Sweller and Clark state that direct instruction (DI) enables the teacher to structure and guide learners in a manner that aids recall, transfer, application and problem solving. The implication being that DI should precede more learner-centric methods, such as discovery learning (Mincu 2015; Rowe 2006). Furthermore, Mincu cites Reynolds et al. (2014) stating that constructivist approaches may be less appropriate learners who are younger, low-attaining or low socio-economic status. However, Reynolds et al. discuss this in the context of 'structured teaching' that emphasises knowledge and application, rather than DI, and refer to neither constructivism nor discovery learning, as implied by Mincu. DI is well supported by evidence from cognitive science (Kirschner et al. 2006; Rowe 2006) and shares similarities with demonstration as described by Petrina (2007). We will explore similarities later in this section.

Kirschner et al. are critical of what they describe as constructivist approaches, which they characterised with a number of more learner-centric approaches, including discovery learning; baldly stating "students learn so little from a constructivist approach" (2006, p. 79). However, they also adopt ideas more familiar in constructivist approaches, such as scaffolding (Wood et al. 1976). Rowe and Reynolds et al., adopt a less polarised critique, recognising the limitations of discovery learning and emphasising the benefits of DI for certain learners. Sternberg notes "extremes are not useful" (2009, p. xi) in the debate between constructivist and explicit instruction, and that both the teaching of facts and for creativity have their place. Therefore, the consideration of demonstration as either a 'constructivist' or 'not constructivist' pedagogical approach may be a somewhat redundant exercise. Considering pedagogical choices on restrictive-expansive framework, with DI tending towards the restrictive end of the continuum, the D\&T teacher may adopt approaches without the fear of transgressing notional theoretical boundaries.

Effective guidance and examples, as promoted in DI, can avoid learners becoming frustrated or developing misconceptions when learning new concepts or processes. Hattie (2009) ranks DI amongst the most effective teaching approaches, acknowledging the 
tension with constructivist approaches; clarifying the distinction between "teacher led talking from the front" (p. 204) and DI, as described by Adams and Engelmann (1996).

In a nutshell: the teacher decides the learning intentions and success criteria, makes them transparent to the students, demonstrates them by modelling, evaluates if they understand what they have been told by checking for understanding, and re-telling them what they have told by tying it all together with closure. (Hattie 2009, p. 206)

The pedagogical process of modelling (and explaining), inferred by Hattie, is at the heart of direct instruction; as a planned and intentional activity, evaluated and revisited. In other words, DI is more than a teacher standing in front of the class, engaging in a one-way transfer of knowledge. Kirschner et al. favour DI for cognitive load reduction. However Martin (2016) draws on research from education psychology and adopts a more nuanced approach recognising that a range of approaches along a restrictive-expansive pedagogical continuum should be adopted for Load Reduction Instruction (LRI):

[LRI is] an umbrella term that encompasses instructional models such as direct instruction and explicit instruction - as well as some less structured approaches to instruction (e.g. guided discovery learning) - that seek to optimally manage the cognitive burden on students in order to enhance their learning and achievement. (Martin 2016, p. 5)

\section{Social learning theory}

Bandura (1977) proposed that learning takes place within social context through observation, imitation and modelling. Social learning theory (SLT) bridges the gap between behavioural and cognitive theories of learning, making a distinction between an observer 'acquiring' and 'performing' a learnt behaviour, akin to Ryle's (1949) 'knowing that' and 'knowing how'. In D\&T, teacher modelling utilises the social interactions between teacher and learner support increasing autonomy; with the intention that learners both know about (acquire) a process being demonstrated and are able to demonstrate (perform) that they know how to apply the knowledge. This is reflected in the aforementioned psychomotor domains, in Dave's (1967) imitation to naturalisation and Simpson's (1972) perception to complex overt response (Table 1); acknowledging the progression from the acquisition of knowledge through to action (performance). Therefore, demonstration that promotes learning and progress should be informed by an understanding of the learners and the learning intentions, in the context of a restrictive-expansive framework.

SLT describes four separate processes involved with observation learning: attention, retention, production and motivation. These are largely internal cognitive processes within the learner and the teacher's role during and after demonstration is to recognise and accommodate these processes. SLT implies that when planning for and delivering instruction, the teacher must ensure that learners are supported and able to pay attention to the matter in hand, including being able to accurately observe with their interest being aroused. During and after instruction, consideration must be given to learners' retention, their ability to understand and encode the information to memory, which can be support retrieval practice (Brown et al. 2014). The role of the teacher also includes supporting learners' reproduction of observational learning with autonomy through structured teaching and feedback (Hattie 2009; Adams and Engelmann 1996). Both the quality of the instruction and subsequent activity learners perform, provide opportunities to motivate learners, and the role of the teacher is to balance internal and external incentives. Internal motivation becomes more 
important as learners engage with more learner-centred activity. Ultimately, the intention in D\&T is motivation to act, typically in design and make activities, which are foundational to the subject (Kimbell et al. 1991).

\section{Summary}

McLain (2017) explored the implications of social constructivist theories and the role of the teacher as a 'more knowledgeable other' (Vygotsky 1978). Cognitive load theories of learning provide a counterargument, raising questions regarding the effectiveness of constructivist approaches (Kirschner et al. 2006). However, this is specifically directed at minimal instruction approaches, such as discovery learning. Others moderate the binary 'direct instruction good, discovery learning bad' view, suggesting that evidence indicates that it is more effective to begin with direct instruction and the use of a wide range of pedagogies is desirable (Mincu 2015; Hattie 2009; Rowe 2006). Bandura's (1977) social learning theory goes some way to bridge the gap between the cognitive load (behaviourist) and the cognitive theories of learning, focusing on the role of observation by the learner; providing an insight into the early stages of a learner's engagement with new knew knowledge. This aligns with Simpson's (1972) perception and Dave's (1967) imitation stages of the psychomotor domain, which rely the learner observing and imitating the teacher (expert). Thus focusing the teacher's preparation on the learner and learning, alongside subject content knowledge. CLT and DI focus on the structuring of learning by a teacher, to combine subject knowledge with an understanding of how learners learn and the teacher's ability to articulate said knowledge (i.e. break down and effectively present new or complex processes or ideas). This tripartite view of knowledge for teaching is ranked within the zone of desirable effects in Hattie's meta-analysis of teacher knowledge (2009, pp. 113-115).

Therefore, the focus on 'demonstration' as a signature pedagogy in D\&T is on the initial interactions between the learner (as a novice) and the teacher (as an expert); with the act of demonstration being a form of teacher modelling and explanation, concerned with developing new or more advanced practical knowledge. A comparison of Petrina's (2007) four common components of demonstration with Hattie's (2009) description of seven major steps involved in DI, reveals similar intentions and actions (Table 2). Furthermore, in the context of design and make activity, DI's guided and independent practice are inferred in a D\&T context, and Petrina clearly links demonstration with practice.

DI and Petrina's components of demonstration also align with the cognitive apprenticeship framework developed by Collins et al. (1991), who present four dimensions that contribute to the learning environment: content, method, sequence and sociology (p. 12). This framework is more wide-ranging than both DI and demonstration, considering pedagogical

Table 2 Comparing direct instruction and demonstration

\section{Hattie's steps in direct instruction}

1. Clear learning intentions for the lesson

2. Clear success criteria of performance

3. Build commitment and engagement

4. Selecting appropriate methods

5. Incorporating guided practice

6. Reviewing and clarifying

7. Independent practice
Petrina's components of demonstration

1. Introduction to what will be demonstrated

2. Relevance of the demonstration

3. Effective and safe execution of a process

4. Recap, summary and next steps 
method as part of curriculum design. Similar to the findings in McLain (2017; Figure 1), the content dimension considers domain knowledge ("competence with subject knowledge') and control strategies ('effective classroom management'), as well as heuristic and learning strategies. The wider concerns with sequence and sociology focussing on the role of the teacher to plan for learning and progress to support and challenge all learners. The method dimension describes five elements, the first three of which (modelling, coaching and scaffolding) are considered the "core of cognitive apprenticeship" (p. 13), and strongly align with the both Hattie's DI and Petrina's demonstration frameworks. Collins, Brown and Holum describe the method dimension as "ways to promote the development of expertise...

Modelling teacher performs a task so students can observe,

Coaching teacher observes and facilitates while students perform a task,

Scaffolding teacher provides supports to help the student perform a task,

Articulation teacher encourages students to verbalize their knowledge and thinking,

Reflection teacher enables students to compare their performance with others,

Exploration teacher invites students to pose and solve their own problems" (p. 15).

The next two elements (reflection and reflection) focus on how learners process their understanding of expert technique, and the last (exploration) on autonomous application, which aligns with latter domains of psychomotor learning described above. In D\&T, this is most often expressed through design and making activities.

An interim definition of 'demonstration' in D\&T, for this study, is that it is a form of teacher modelling and explaining concerned with enabling learners to understand and apply with new knowledge (procedural) in and a practical context. Typically (although not exclusively) in a design and make context, where an 'expert' teacher visually and verbally prepares 'novice' learners to engage with practical activity. In addition to the procedural knowledge for learners to engage with D\&T activity, effective demonstration should also consider aspects of the safe application, wider context and implications of the knowledge in question (Petrina 2007, p. 14). The sections below will outline the research methods and findings, exploring teacher educator perceptions on the nature of demonstration as a signature pedagogy; and what is considered to be effective practice when demonstrating skills and knowledge. A signature pedagogy being an approach to teaching and/or learning, characteristic (or commonly used) within particular discipline that influence how the subject is taught.

\section{Theoretical framework and research design}

This study was conducted using Q Methodology (Watts and Stenner 2012), which focuses on participants' subjective beliefs or "first person viewpoints" (p. 4) "in pursuit of an explanation and new insight" (p. 39). It explores teacher educators' views on the 'demonstration' in D\&T. The breadth of views within the community (referred to as the Concourse) was encapsulated in a set of 62 statements (Q-Set), developed for the initial study of teachers' views, described by McLain (2017) and McLain et al. (2015), was adopted for this study. The statements include propositions that include:

- The teacher addresses learners misconceptions as they arise; 
- The teacher scans the room after the demonstration to monitor learners' progress;

- The teacher waits for learners to attempt a task before intervening.

In Q Methodology, the set of statements tend to represent the broad range of views held by a community, and therefore include statements that often engender strong disagreement. This is not considered to be a requirement, but some participants can find it difficult to sort statements along a continuum from 'most agree' to 'most disagree'. The statements in this study do not represent extremes of views, and some participants reported difficulty in sorting some statements.

Participants followed two stages in which they sorted the statements. In the first stage, the statements were categorised as essential, desirable or optional. The second stage was to further sort the statements along a most agree/most disagree continuum. This is known as a forced-choice frequency distribution, where there are fewer spaces to place statements at the extremes of the continuum, compared to the 'middle ground' (Fig. 2). In this study, a 13-point scale was used, with two spaces at the extremes and eight in the centre. This restriction forces participants to make considered choices about what they most agree or most disagree with.

The study was deployed and completed online using QSortWare (Pruneddu 2014) to capture responses from teacher educators in initial teacher education (ITE) providers in England. The analysis of data was conducted using the PQMethod software (Schmolck 2014) and is presented below in Tables 4, 5, 6 and 7. The sample is purposive (Guba 1981) and participants were recruited through an online D\&T teacher educator forum. As such, the analysis and discussion of findings attempt neither to discern generalizable principles in answer to the research question nor present the sample as representative of the sector. Rather, the study presents views to inform professional conversations and future classroom based inquiry.

Eleven participating teacher educators (Table 3) responded to an invitation on a D\&T email discussion group for teacher educators. The balance was approximately equal between females $(n=6)$ and males $(n=5)$, and all participants had at least 5 years' experience in initial teacher education, with the exception for participant 8 (less than 2 years). There were no statistically significant correlations between gender or D\&T specialism in participants responses. This study extends the pilot study of D\&T teachers (McLain 2017), exploring the subjective values of D\&T teacher educators. When completing the activity, participants were asked to reflect on effective classroom practice, considering the:

- Learning intentions of the demonstration;

- Preparation before the demonstration;

- Timing of the demonstration;

Most disagree

Most agree

\begin{tabular}{|l|l|l|l|l|l|l|l|l|l|l|l|}
\hline & & & & & & & & & & & \\
\hline \\
\hline \multirow{2}{*}{2}
\end{tabular}

Fig. 2 Forced-choice frequency distribution 
Table 3 Sample group $(n=11)$

\begin{tabular}{ll}
\hline Sort & Main D\&T specialism \\
\hline 1 & Other \\
2 & Graphic design \\
3 & Product design \\
4 & Other \\
5 & Graphic design \\
6 & Electronics and control \\
7 & Textiles and fashion \\
8 & Textiles and fashion \\
9 & Product design \\
10 & Electronics and control \\
11 & Electronics and control \\
\hline
\end{tabular}

Table 4 Correlation matrix between Q sorts

\begin{tabular}{|c|c|c|c|c|c|c|c|c|c|c|c|}
\hline & 1 & 2 & 3 & 4 & 5 & 6 & 7 & 8 & 9 & 10 & 11 \\
\hline 1 & 100 & 40 & 26 & 53 & 22 & 24 & 27 & 16 & 18 & -34 & 37 \\
\hline 2 & & 100 & 15 & 45 & 12 & 16 & 33 & 11 & 15 & -33 & 45 \\
\hline 3 & & & 100 & 29 & 25 & 31 & 1 & 20 & 30 & -17 & 9 \\
\hline 4 & & & & 100 & 25 & 22 & 35 & 21 & 21 & -35 & 59 \\
\hline 5 & & & & & 100 & 23 & 0 & 12 & 15 & -16 & 26 \\
\hline 6 & & & & & & 100 & 23 & 38 & 14 & -41 & 32 \\
\hline 7 & & & & & & & 100 & -7 & -6 & -42 & 39 \\
\hline 8 & & & & & & & & 100 & 25 & -5 & 26 \\
\hline 9 & & & & & & & & & 100 & -9 & 11 \\
\hline 10 & & & & & & & & & & 100 & -55 \\
\hline 11 & & & & & & & & & & & 100 \\
\hline
\end{tabular}

Table 5 Factor loadings with an $\times$ indicating a defining sort

\begin{tabular}{lllll}
\hline Participant & \multicolumn{2}{l}{ Factor loadings } & \\
\cline { 2 - 5 } & 1 & & 2 & \\
\hline 1 & 0.5929 & $\times$ & -0.4489 & \\
2 & 0.6944 & $\times$ & -0.2660 & \\
3 & -0.0252 & & -0.6533 & $\times$ \\
4 & 0.7064 & $\times$ & -0.4087 & \\
5 & 0.1170 & & -0.4829 & $\times$ \\
6 & 0.0636 & & -0.2836 & \\
7 & 0.6701 & $\times$ & 0.2297 & \\
8 & -0.1445 & & -0.5187 & $\times$ \\
9 & -0.0025 & & -0.7156 & $\times$ \\
10 & -0.5678 & $\times$ & 0.0332 & \\
11 & 0.6772 & $\times$ & -0.2043 & \\
$\%$ expl. var. & 24 & & 19 & \\
\hline
\end{tabular}


Table 6 Consensus statements

\begin{tabular}{|c|c|c|c|c|c|}
\hline \multirow{2}{*}{\multicolumn{2}{|c|}{ Statement }} & \multicolumn{2}{|c|}{ Factor 1} & \multicolumn{2}{|c|}{ Factor 2} \\
\hline & & \multirow{2}{*}{$\frac{\text { Q-SV }}{5}$} & \multirow{2}{*}{$\begin{array}{r}\text { Z-SCR } \\
1.83\end{array}$} & \multirow{2}{*}{$\begin{array}{r}\text { Q-SV } \\
5\end{array}$} & \multirow{2}{*}{$\frac{\text { Z-SCR }}{1.42}$} \\
\hline *17 & The teacher identifies the main points/steps for the learners & & & & \\
\hline *1 & $\begin{array}{l}\text { The teacher gives an overview of the content of the skills or } \\
\text { knowledge being demonstrated }\end{array}$ & 4 & 1.45 & 4 & 1.31 \\
\hline *35 & The teacher identifies hazards and risks for the learners & 4 & 1.12 & 3 & 0.77 \\
\hline *60 & $\begin{array}{l}\text { The teacher makes his/her expectations of the learners' } \\
\text { outcomes clear }\end{array}$ & 3 & 1.03 & 2 & 0.54 \\
\hline 4 & The teacher presents the learning objectives (knowledge/skills) & 2 & 0.65 & 4 & 1.32 \\
\hline *26 & $\begin{array}{l}\text { The teacher uses questioning to enable learners to recall } \\
\text { aspects of the process demonstrated }\end{array}$ & 2 & 0.63 & 1 & 0.42 \\
\hline *32 & $\begin{array}{l}\text { The teacher prepares the demonstration station/area in advance } \\
\text { (e.g. before the lesson) }\end{array}$ & 2 & 0.72 & 1 & 0.32 \\
\hline *3 & The teacher presents their expectations & 1 & 0.6 & 2 & 0.67 \\
\hline 21 & The teacher addresses learners misconceptions as they arise & 1 & 0.42 & -1 & -0.34 \\
\hline *23 & $\begin{array}{l}\text { The teacher uses questioning to probe learners' prior knowledge } \\
\text { from within the unit/project }\end{array}$ & 1 & 0.37 & 1 & 0.19 \\
\hline *38 & Appropriate information about risk is readily available to learners & 1 & 0.6 & 3 & 0.91 \\
\hline *18 & $\begin{array}{l}\text { The teacher 'signposts' or indicates the next steps (i.e. "later in } \\
\text { the lesson..." or "in next lesson...") }\end{array}$ & 0 & -0.12 & 0 & 0.12 \\
\hline 30 & $\begin{array}{l}\text { The teacher prepares and uses examples of the } \\
\text { products/outcomes being demonstrated }\end{array}$ & 0 & -0.27 & 1 & 0.37 \\
\hline *31 & $\begin{array}{l}\text { The teacher prepares examples showing the steps/stages of the } \\
\text { process being demonstrated }\end{array}$ & 0 & -0.07 & 1 & 0.14 \\
\hline *36 & $\begin{array}{l}\text { The teacher prompts learners to identify hazards and risks for } \\
\text { themselves }\end{array}$ & 0 & -0.13 & 0 & -0.28 \\
\hline *39 & $\begin{array}{l}\text { The teacher sets high standards and expectations for the } \\
\text { learners in designing and making activities }\end{array}$ & 0 & -0.2 & -2 & -0.7 \\
\hline${ }^{*} 53$ & $\begin{array}{l}\text { The teacher scans the room after the demonstration to monitor } \\
\text { learners' progress }\end{array}$ & 0 & 0.14 & 2 & 0.54 \\
\hline *56 & $\begin{array}{l}\text { After the demonstration, the teacher moves around the room to } \\
\text { support learners }\end{array}$ & 0 & 0.02 & 2 & 0.54 \\
\hline${ }^{*} 12$ & $\begin{array}{l}\text { The teacher provides a running commentary through the } \\
\text { demonstration }\end{array}$ & -1 & -0.34 & -3 & -0.94 \\
\hline *28 & $\begin{array}{l}\text { The teacher uses questioning to encourage learners to speculate } \\
\text { (e.g. predicting the next step in a process) }\end{array}$ & -1 & -0.55 & -4 & -1.12 \\
\hline${ }^{*} 61$ & $\begin{array}{l}\text { The teacher provides examples of outcomes of a process that } \\
\text { exemplify the skills being modelled }\end{array}$ & -1 & -0.57 & -4 & -1.04 \\
\hline${ }^{*} 6$ & $\begin{array}{l}\text { The teacher refers to the application, of what is being } \\
\text { demonstrated outside the classroom context }\end{array}$ & -2 & -0.81 & -5 & -1.4 \\
\hline *16 & $\begin{array}{l}\text { The teacher uses examples, analogies and/or similes to explain } \\
\text { processes and procedures }\end{array}$ & -2 & -0.68 & -2 & -0.62 \\
\hline *44 & $\begin{array}{l}\text { The teacher encourages learners to participate in fault finding } \\
\text { and quality control }\end{array}$ & -2 & -0.65 & -1 & -0.41 \\
\hline *25 & $\begin{array}{l}\text { The teacher questioning to probe learners' prior knowledge from } \\
\text { other subjects }\end{array}$ & -3 & -0.93 & -2 & -0.6 \\
\hline *52 & $\begin{array}{l}\text { The teacher encourages learners to reflect on values (e.g. the } \\
\text { impact of a technology on society, the environment, etc.) }\end{array}$ & -3 & -1.09 & -2 & -0.5 \\
\hline 54 & $\begin{array}{l}\text { The teacher waits for learners to attempt a task before } \\
\text { intervening }\end{array}$ & -3 & -0.94 & -1 & -0.3 \\
\hline *15 & $\begin{array}{l}\text { The teacher make reference to cause and effect of decisions } \\
\text { and/or actions }\end{array}$ & -4 & -1.17 & -2 & -0.73 \\
\hline 41 & $\begin{array}{l}\text { The teacher enables learners to identify alternative actions or } \\
\text { choices that they can make (e.g. design, make, evaluate, etc.) }\end{array}$ & -4 & -1.13 & -1 & -0.43 \\
\hline *14 & $\begin{array}{l}\text { The teacher makes reference to relationships with other related } \\
\text { concepts (e.g. mathematical, scientific, technological, etc.) }\end{array}$ & -5 & -1.31 & -3 & -0.8 \\
\hline
\end{tabular}

All listed statements are non-significant at $P>.01$, and those asterisked $\left(^{*}\right)$ are also non-significant at $P>.05$ 
Table 7 Distinguishing statements

\begin{tabular}{|c|c|c|c|c|c|}
\hline \multirow{2}{*}{\multicolumn{2}{|c|}{ Statement }} & \multicolumn{2}{|c|}{ Factor 1} & \multicolumn{2}{|c|}{ Factor 2} \\
\hline & & \multirow{2}{*}{$\frac{\text { Q-SV }}{6}$} & \multirow{2}{*}{$\begin{array}{r}\text { Q-SV } \\
1.96\end{array}$} & \multirow{2}{*}{$\begin{array}{r}\text { Z-SCR } \\
-5\end{array}$} & \multirow{2}{*}{$\begin{array}{r}\text { Z-SCR } \\
-1.33\end{array}$} \\
\hline *11 & $\begin{array}{l}\text { The teacher gives clear verbal explanations of processes and } \\
\text { procedures }\end{array}$ & & & & \\
\hline *37 & The teacher is competent to use equipment safely & 6 & 2 & -6 & -2.57 \\
\hline *5 & $\begin{array}{l}\text { The teacher presents the learning outcomes (i.e. what learners will } \\
\text { do or be able to do as a result) }\end{array}$ & 5 & 1.57 & 0 & -0.15 \\
\hline *13 & $\begin{array}{l}\text { The teacher gives clear models/examples processes and } \\
\text { procedures }\end{array}$ & 5 & 1.49 & 2 & 0.53 \\
\hline *2 & The teacher uses technical language/terminology and key words & 4 & 1.35 & -4 & -1.00 \\
\hline *8 & $\begin{array}{l}\text { The teacher uses staged demonstrations, breaking down more } \\
\text { complex process into separate (linked) demonstrations }\end{array}$ & 4 & 1.38 & -4 & -1.08 \\
\hline *10 & $\begin{array}{l}\text { The teacher adapts their approach and style of demonstration to } \\
\text { the learners, dependent on age, ability, prior experience, etc. }\end{array}$ & 3 & 0.97 & -5 & -1.71 \\
\hline *48 & The teacher has 'presence' within the classroom & 3 & -0.34 & 3 & 0.72 \\
\hline *62 & $\begin{array}{l}\text { The teacher ensures that all learners know what they need to do } \\
\text { to make progress }\end{array}$ & 3 & 0.81 & -1 & -0.30 \\
\hline 45 & $\begin{array}{l}\text { The teacher ensures that they make eye contact with members of } \\
\text { the whole group }\end{array}$ & 3 & -0.45 & 2 & 0.70 \\
\hline *7 & $\begin{array}{l}\text { The teacher demonstrates skills and knowledge that learners will } \\
\text { apply within the lesson }\end{array}$ & 2 & 0.61 & -1 & -0.41 \\
\hline *27 & $\begin{array}{l}\text { The teacher uses questioning to probe understanding of concepts, } \\
\text { process and procedures }\end{array}$ & 2 & 0.73 & -6 & -2.34 \\
\hline *59 & $\begin{array}{l}\text { The teacher explains what learners are expected to do to make } \\
\text { progress }\end{array}$ & 2 & 1.04 & 0 & 0.00 \\
\hline *22 & $\begin{array}{l}\text { As part of the planned demonstration, the teacher addresses } \\
\text { common misconceptions around technical terms, concepts, etc. }\end{array}$ & 1 & 0.25 & -2 & -0.59 \\
\hline *24 & $\begin{array}{l}\text { The teacher questioning to probe learners' prior knowledge from } \\
\text { previous D\&T units/projects }\end{array}$ & 1 & 0.44 & -3 & -0.75 \\
\hline *47 & $\begin{array}{l}\text { The teacher scans and monitors the group to ensure that learners } \\
\text { are safe }\end{array}$ & 1 & 1.01 & -3 & -0.79 \\
\hline${ }^{*} 50$ & $\begin{array}{l}\text { The teacher encourages learners to 'think-out-loud' to consolidate } \\
\text { knowledge and understanding }\end{array}$ & 0 & -0.99 & 3 & 0.76 \\
\hline *34 & $\begin{array}{l}\text { The teacher uses other support staff (i.e. technician or teaching } \\
\text { assistant) during, and after, the demonstration to support learners }\end{array}$ & -1 & -0.54 & 5 & 1.90 \\
\hline${ }^{*} 42$ & $\begin{array}{l}\text { The teacher plans and uses extension or enrichment activities for } \\
\text { able learners }\end{array}$ & -1 & -0.47 & 1 & 0.47 \\
\hline *46 & $\begin{array}{l}\text { The teacher scans and monitors the group, as they are teaching, } \\
\text { to ensure that the learners are engaged }\end{array}$ & -1 & 0.16 & -3 & -0.99 \\
\hline${ }^{*} 49$ & $\begin{array}{l}\text { The teacher can modify their tone when talking to/with different } \\
\text { sized groups and in different situations }\end{array}$ & -1 & -0.18 & 5 & 1.46 \\
\hline *33 & $\begin{array}{l}\text { The teacher uses resources, such as instruction sheets, } \\
\text { slideshows or videos, after the dem onstration to support learners }\end{array}$ & -2 & -0.59 & 1 & 0.36 \\
\hline${ }^{*} 43$ & $\begin{array}{l}\text { The teacher encourages/supports learners to dem onstrate skills } \\
\text { and knowledge to their peers }\end{array}$ & -2 & -0.69 & 0 & 0.13 \\
\hline *58 & $\begin{array}{l}\text { The teacher uses questioning to ascertain what a learner } \\
\text { understands, when they have not fully understood the } \\
\text { demonstration }\end{array}$ & -2 & 0.76 & -1 & -0.41 \\
\hline *51 & $\begin{array}{l}\text { The teacher explains the function and/or context of the matter (i.e. } \\
\text { knowledge and/or skill) being demonstrated }\end{array}$ & -3 & -0.84 & 0 & 0.13 \\
\hline${ }^{*} 55$ & $\begin{array}{l}\text { The teacher encourages learners to support each other before } \\
\text { seeking the assistance of the teacher }\end{array}$ & -3 & -1.16 & 3 & 0.75 \\
\hline *40 & $\begin{array}{l}\text { The teacher identifies alternative actions or choices learners can } \\
\text { or need to do (e.g. design, make, evaluate) }\end{array}$ & -4 & -1.22 & 3 & 1.28 \\
\hline *57 & $\begin{array}{l}\text { The teacher shows/explains the process/skill to individuals who } \\
\text { have misunderstood processes or concepts shortly after a } \\
\text { demonstration }\end{array}$ & -4 & -0.75 & 0 & 0.11 \\
\hline *19 & $\begin{array}{l}\text { The teacher models diagnostic processes, such as using testing } \\
\text { equipment to fault-find or the application of scientific knowledge } \\
\text { from an observation }\end{array}$ & -5 & -1.23 & 4 & 1.41 \\
\hline *29 & $\begin{array}{l}\text { The teacher uses visual resources, such as images, photographs } \\
\text { and diagrams, to enhance their demonstrations }\end{array}$ & -5 & -1.43 & 0 & -0.07 \\
\hline${ }^{*} 9$ & $\begin{array}{l}\text { The teacher models/explains the whole process in one } \\
\text { demonstration }\end{array}$ & -6 & -2.09 & 6 & 2.06 \\
\hline${ }^{*} 20$ & The teacher uses ICT to simulate or model process or products & -6 & -2.18 & 6 & 2.34 \\
\hline
\end{tabular}

$P<0.05$; asterisk (*) indicates significance at $P<0.01$ 
- Learner engagement during the demonstration;

- Learner activity during and after the demonstration.

Table 4 shows the initial correlations between Q-Sorts and indicates correlations between the participants; ranging from a strong positive correlation between participants 4 and 11, to a strong negative correlation between participants 7 and 10. Participant 10's responses showed a negative correlation to the other participants, indicating significantly different pattern of preferences when ranking the statements. This mirrors findings from the pilot study (McLain 2017), which acknowledged that there appeared to be "no 'one size fits all' approach". Furthermore, the factor analysis identified three distinct groupings (factors) of participants with similar responses, as outlined below, with one group comprised of one participant. The factor analysis used in Q Methodology is exploratory and was developed by Stephenson (1935) as an adaptation of the Spearman method (Watts and Stenner 2012, p. 21).

The initial analysis of data in Q Methodology uses factor analysis to identify correlations. Unlike normal ( $\mathrm{R}$ method) factor analysis, which find correlations between variables (e.g. a set of statements) across sample of subjects (i.e. the participants), Q Methodology seeks correlations between participants across a sample of the statements. The 'factors' extracted from the data are, therefore, groups of participants with similar views-as judged by how they have ranked the statements along the aforementioned forced-choice frequency distribution (Fig. 2).

PQMethod initially extracted eight factors, three of which had Eigenvalues (EV) above 1.00, indicating the statistical strength (Watts and Stenner 2012, p. 105). Initially, Factor One had an EV of 3.5994 and Factor Two 1.5627. Factor Three, with an EV of 1.0299 and comprised of one participant (No. 6), and was subsequently deselected for this study, prior to further analysis and factor rotation. Q Methodology experts advise that, typically, one factor can be expected to emerge for every six to eight participants (Watts and Stenner 2012, p. 107). Table 5 indicates the factor loadings for the each participant and the Factor with which they are identified. In Q Methodology, the Factor refers to the groupings of participants with similar responses, identified through the factor analysis.

Table 6 (consensus statements) and Table 7 (distinguishing statements) present all 62 statements, ranked for each Factor. Consensus statements are those where there is general agreement between the participants. Conversely, distinguishing statements are those where there is more disagreement between the participants. Consensus statements may be more useful in identifying patterns and general principles, whereas distinguishing statements more useful for exploring differing views and establishing the boundaries of a matter.

\section{Analysis of findings}

From this point in the analysis of data, the term 'Factor' will be replaced with 'Group'.

\section{The consensus statements}

The 30 items from the Q-Set where there was consensus between both groups (Table 6) show similar results to the previous study (McLain 2017), with a strong core of statements that align with the competence of the teacher, with regard to D\&T subject knowledge (Fig. 1). Alongside subject knowledge, the highest ranked items also emphasise 
that an effective demonstration relies on pedagogical knowledge (and skill), including the structuring and sequencing of learning (e.g. statement 17), promoting safe practice (e.g. statements 35 and 38), questioning for recall and reinforcement (e.g. statements 26 and 23) and addressing misconceptions (e.g. statement 21). Statements of this nature rank with $\mathrm{a}+1$ or above Q-Sort Value (Q-SV) for both groups, in the consensus statements (Table 6) - the Z Scores (Z-SCR) are the weighted average of the scores for participants' responses in each group (factor). There was also a number of the middle to lower ranked items that relate to classroom management, including managing risk, whole class awareness and explicit expectations.

Similar to previous findings (McLain 2017), statements relating consolidation of learning and facilitation of learning were ranked on the negative (most disagree) end of the spectrum. Consolidation appears to rank higher, with a cluster of four statements relating to questioning in the mid-range. Items relating to the autonomy of the learner, such as identifying hazards and risks for themselves, fault finding and reflecting on values, appear lower down the rank order. However, a negative value does not necessarily imply a participant's disagreement with a statement, rather a relative lower ranking compared to others in the context of the study.

\section{The distinguishing statements}

The 32 items from the Q-Set where there was a lack of consensus between both groups (Table 7) shows a similar favouring of statement relating to teacher knowledge in the higher ranked items. However, there is less clustering of statements relating to the other areas. This may indicate that this set of statements may be useful for future studies, with potential to identify groups with more polarised views, and thus potentially groups (factors) with more distinct characteristics.

\section{The groups}

Two distinct groups of participants with similar trends in their responses emerge from the factor analysis. A summary of the data for each group is presented side-by-side, below, for comparison. Following a brief description of the composition of each group, the analysis of data is organised in five bands, based on their rank order:

- 'Top items' $(+6$ to +5$)$;

- 'Items sorted higher than others' $(+4$ to +2$)$;

- 'Items tied with others (mid-range)' (+ 1 to -1$)$;

- Items sorted lower than others $(-2$ to -4$)$

- Bottom items $(-5$ to -6$)$.

Cross-references to statements are indicated in brackets, below, with the statement number 1-62 followed by the ranking within the group, +6 to -6 . For example, (20:6) indicates the highest ranking for statement 20, "The teacher uses ICT to simulate or model process or products", whereas $(7:-1)$ indicates a moderately low ranking for statement 7, "The teacher demonstrates skills and knowledge that learners will apply within the lesson". 


\section{Description of the composition of each Group 1: the teacher as expert}

Group 1 was comprised of 6 teacher educators, 4 of whom were male and 2 female, with two identifying their main specialism as electronics and control, one as graphic design, one as textiles and fashion, and two did not identify a specialism.

\section{Description of the composition of each Group 2: the teacher as facilitator}

Group 2 was comprised of 4 teacher educators, all of who were female, with 2 identifying their main specialism as product design, one as graphic design and one as textiles and fashion.

Group 1 appear to value a planned and structured demonstration, with the responses indicating a focus on the learning outcomes (5:5), identification of the main points or steps (17:5) and use of clear models or examples (13:5) of processes and procedures, underpinned by clear verbal explanations (11:6).

Group 2 also value a planned and structured learning experience, where the knowledge is broken down into its components parts (17:5), modelling and explaining a process in one demonstration (9:6), supported by ICT to stimulate or support understanding of a process or product (20:6). This group also highlight the use of other adults in the classroom to support learners (34:5), and ability to modify their tone in response to different groups and situations (49:5); ranking of statements with a learner focus at a higher level than Group 1. Hence, the more facilitative characterisation of this group.

Whilst Groups 1 and 2 appear to hold largely similar views (Table 8), the highest ranked items in the sort begin to suggest their overarching themes and characteristics. Both value planning and the role of the teacher to break down complex knowledge, whilst the focus of Group 1 appears to be on aspects relating to the transmission of content knowledge and teacher-centric approaches, whereas Group 2 focus on personalised and learner-centric approaches.

Continuing to focus on the higher ranked items (Table 9), a holistic focus emerges in Group 1, beginning with the teacher providing an overview of the skills or knowledge being demonstrated (1:4), in common with the other group, making links to learning and made clear through expectations of outcomes (60:4), what learners need to do (59:3) and the teachers role to enable them (62:3) to make progress. In contrast with the other group,

Table 8 Highest ranked items

\begin{tabular}{ll}
\hline Group 1 & Group 2 \\
\hline $\begin{array}{l}\text { The teacher gives clear verbal explanations of } \\
\text { processes and procedures (11:6) }\end{array}$ & $\begin{array}{c}\text { The teacher models/explains the whole process in one } \\
\text { demonstration }(9: 6)\end{array}$ \\
$\begin{array}{c}\text { The teacher identifies the main points/steps for the } \\
\text { learners }(17: 5)^{*}\end{array}$ & $\begin{array}{c}\text { The teacher uses ICT to simulate or model process or } \\
\text { products }(20: 6)\end{array}$ \\
$\begin{array}{c}\text { The teacher gives clear models/examples processes } \\
\text { Thd procedures (13:5) }\end{array}$ & $\begin{array}{c}\text { leacher identifies the main points/steps for the } \\
\text { learners }(17: 5)^{*}\end{array}$ \\
$\begin{array}{c}\text { The teacher presents the learning outcomes (i.e. } \\
\text { what learners will do or be able to do as a result) } \\
\text { (5:5) }\end{array}$ & $\begin{array}{l}\text { teaching assistant) during, and after, the demonstra- } \\
\text { tion to support learners (34:5) } \\
\text { The teacher can modify their tone when talking to/ } \\
\text { with different sized groups and in different situa- } \\
\text { tions (49:5) }\end{array}$ \\
\end{tabular}


Table 9 Items sorted higher than others

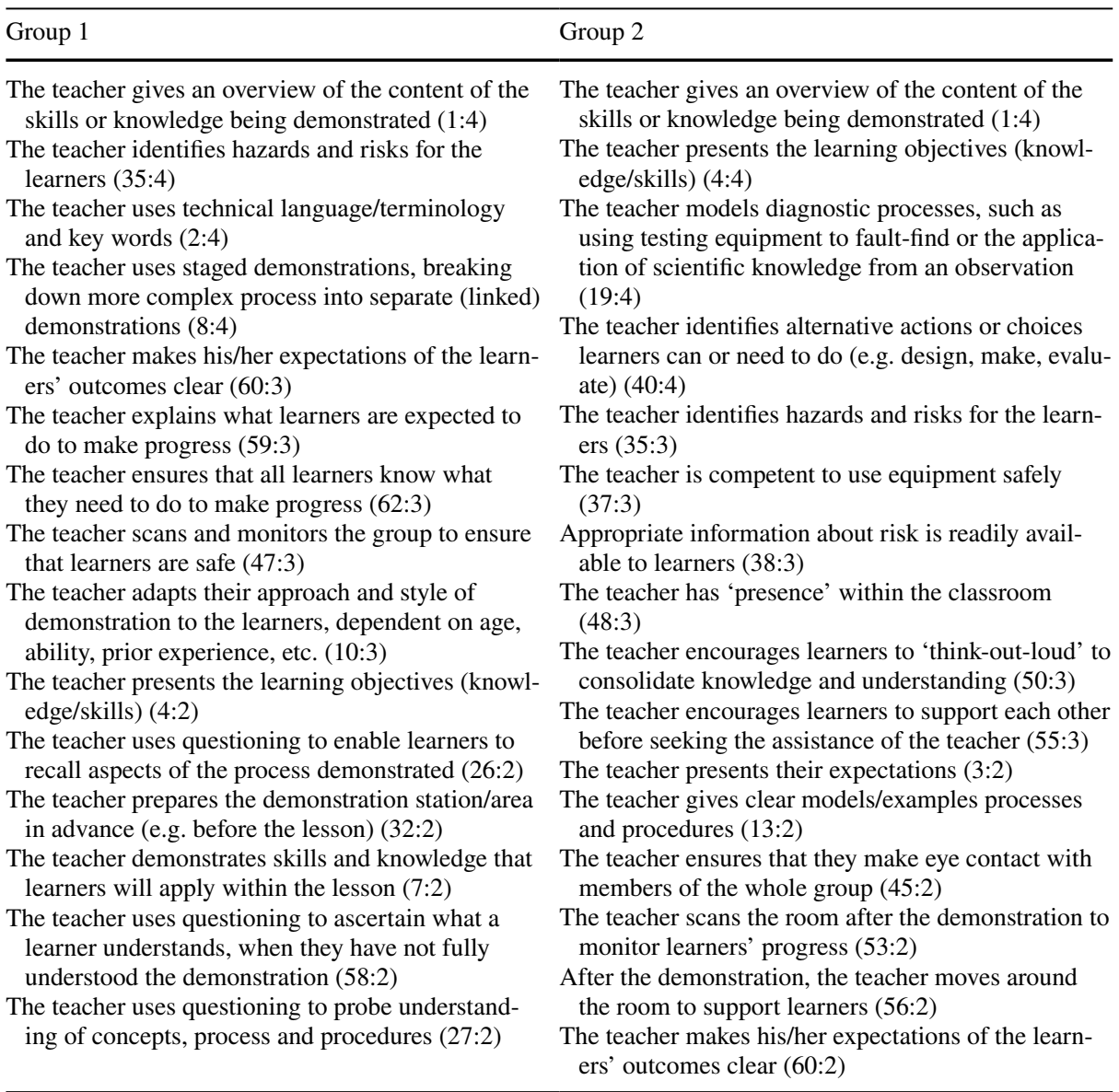

Group 1 consider the didactics of breaking down more complex processes in separate, staged demonstrations (8:4), and the use of technical language and terminology (2:4) to be important, alongside demonstrating knowledge and skill in the context of the lesson in which it will be applied (7:2).

The common ground between Groups 1 and 2 are in relation to the importance of learning objectives (statement 4) and outcomes (statement 60), identification of hazards and risks (statement 35 ) and previewing content of a demonstration (statement 1). Similar themes also emerge through other statements, including preparation (statement 32), scanning and monitoring for learners' safety (Group 1, 47:7; Group 2, 53:2). However, Group 1 identify pedagogical dimensions in the differentiation of approaches for the learners (10:3) and the use of questioning for recall (26:2) and probing understanding following a demonstration (58:2) and of concepts, process and procedures (27:2); highlighting an adaptive approach which is underpinned by teachers' pedagogical and subject knowledge.

For Group 2, the wider considerations include clear expectations of learning and progress $(1: 4,4: 4,3: 2$, and 60:2), including “...models/examples processes..." (13:2) and application of the knowledge being demonstrated, including modelling diagnostic 
processes (19:4) or peer support (55:3), application of knowledge in other contexts (40:4) and encouraging learners to speculate (50:3). In addition, they identify classroom management, through safe use of equipment (37:3), identifying and providing information about hazards and risks for learners (35:3 and 38:3), and whole class presence (48:3), awareness through visually scanning the room, during (45:2) and after (53:2) demonstrations, and moving "around the room to support learners" (60:2). This demonstrates a range of pedagogical and contextual knowledge in the planning and delivery.

For participants in Group 1, subject knowledge is also a feature of the mid-range responses (Table 10), including the addressing of misconceptions through planning $(22:+1)$ and as they arise $(21:+1)$. Consideration was also given to health and safety in their competent use of equipment $(37:+1)$ and risk assessment $(38:+1)$, including prompting learners to "identify hazards and risks for themselves" (36:0). Classroom management also underpins the pedagogic knowledge highlighted in the highest ranked responses, with whole class awareness through scanning and monitoring for engagement (46:0 and 45:-1) and progress (53:0). Fundamental pedagogic skills of modifying tone for different situations (49:0) and moving around the room following demonstrations to support learners (56:0) contribute to the teacher's presence in the classroom (48:-1). A relate aspect of classroom management, which also links to planning and organisation is the use of support staff during, and after, the demonstration to support learners (34:-1). A third aspect of the mid-range statements for this group is the teacher's pedagogical knowledge, through questioning to probe prior knowledge (23:1 and 24:1) and encourage speculation (28:-1), and exemplification of expectations (3:1 and 39:0), staged of a process (31:0) and final outcomes (30:0 and 61:-1).

In Group 2, mid-range responses include, planning for teacher-led learning through preparation of the demonstration area (32:1), using examples of stages of a process (31:1) products/outcomes (30:1), learning resources $(33: 1,29: 0)$ and extension or enrichment activities for able learners (42:1). Delivery of teacher-led learning should also, make explicit to learners, what they will do, or be able to do (5:0), the next steps (18:0) and what they need to do to make progress $(62:-1,59:-1)$ following a demonstration. In addition, this group identify the use of questioning for recall (26:1), probing knowledge (23:1) and understanding (58:-1). It may be noteworthy that questioning for knowledge appears to be given priority over understanding; and encouraging learner autonomy through learners identifying hazards and risks for themselves (36:0), peer demonstrations (43:0), attempting a task before the teacher intervenes (54:-1), engaging in fault finding and quality control (44:-1), and identifying alternative options (41:-1). Teacher subject knowledge is ranked as moderately important, in teachers' explanations (51:0) and modelling (7:-1), targeting of personalised support (57:0), and addressing misconceptions as they arise in the lesson (21:-1) - it should be noted that planning for misconceptions (22:-2) was ranked below addressing them in context, indicating that there is an expectation of teachers identifying and address them within the lesson. An implication of this view is that teachers' tacit subject knowledge may play an important role in learning, albeit not taking prime position.

Whilst statements with lower rankings (Table 11) do not indicate that the members of this group believe they are unimportant, they suggest that some categories of activity are relatively more important than others.

For Group 1, independent learning is ranked at lower end of the continuum, with less importance given to peer support (41:-4) and demonstrations (43:-2), encouragement to engage with fault-finding or quality control $(44:-2)$, consolidating learning through learner dialogue (50:-3), probing learning from other subjects $(25:-3)$ and identifying alternative actions or choices (40:-4 and 41:-4). Less emphasis is also given to the activity of 
Table 10 Items tied with others (mid-range)

Group $1 \quad$ Group 2

The teacher is competent to use equipment safely (37:1)

Appropriate information about risk is readily available to learners $(38: 1)$

The teacher presents their expectations (3:1)

The teacher uses questioning to probe learners' prior knowledge from within the unit/project (23:1)

The teacher addresses learners misconceptions as they arise (21:1)

As part of the planned demonstration, the teacher addresses common misconceptions around technical terms, concepts, etc. $(22: 1)$

The teacher questioning to probe learners' prior knowledge from previous D\&T units/projects (24:1)

The teacher scans and monitors the group, as they are teaching, to ensure that the learners are engaged (46:1)

The teacher can modify their tone when talking to/ with different sized groups and in different situations (49:0)

The teacher scans the room after the demonstration to monitor learners' progress (53:0)

After the demonstration, the teacher moves around the room to support learners (56:0)

The teacher prepares and uses examples of the products/outcomes being demonstrated (30:0)

The teacher prepares examples showing the steps/ stages of the process being demonstrated (31:0)

The teacher 'signposts' or indicates the next steps (i.e. "later in the lesson..." or "in next lesson...") (18:0)

The teacher prompts learners to identify hazards and risks for themselves (36:0)*

The teacher sets high standards and expectations for the learners in designing and making activities (39:0)

The teacher uses other support staff (i.e. technician or teaching assistant) during, and after, the demonstration to support learners (34:-1)

The teacher has 'presence' within the classroom (48:-1)

The teacher ensures that they make eye contact with members of the whole group (45:-1)

The teacher plans and uses extension or enrichment activities for able learners (42:-1)

The teacher provides a running commentary through the demonstration $(12:-1)$

The teacher uses questioning to encourage learners to speculate (e.g. predicting the next step in a process) $(28:-1)$

The teacher provides examples of outcomes of a process that exemplify the skills being modelled (61:-1)
The teacher uses questioning to probe learners' prior knowledge from within the unit/project (23:1)

The teacher uses questioning to enable learners to recall aspects of the process demonstrated (26:1)

The teacher prepares and uses examples of the products/outcomes being demonstrated (30:1)

The teacher prepares examples showing the steps/ stages of the process being demonstrated (31:1)

The teacher prepares the demonstration station/area in advance (e.g. before the lesson) (32:1)

The teacher uses resources, such as instruction sheets, slideshows or videos, after the demonstration to support learners (33:1)

The teacher plans and uses extension or enrichment activities for able learners (42:1)

The teacher presents the learning outcomes (i.e. what learners will do or be able to do as a result) (5:0)

The teacher 'signposts' or indicates the next steps (i.e. "later in the lesson..." or "in next lesson...") (18:0)

The teacher uses visual resources, such as images, photographs and diagrams, to enhance their demonstrations (29:0)

The teacher prompts learners to identify hazards and risks for themselves (36:0)

The teacher encourages/supports learners to demonstrate skills and knowledge to their peers (43:0)

The teacher explains the function and/or context of the matter (i.e. knowledge and/or skill) being demonstrated (51:0)

The teacher shows/explains the process/skill to individuals who have misunderstood processes or concepts shortly after a demonstration (57:0)

The teacher explains what learners are expected to do to make progress (59:0)

The teacher demonstrates skills and knowledge that learners will apply within the lesson $(7:-1)$

The teacher addresses learners misconceptions as they arise (21:-1)

The teacher enables learners to identify alternative actions or choices that they can make (e.g. design, make, evaluate, etc.) $(41:-1)$

The teacher encourages learners to participate in fault finding and quality control (44:-1)

The teacher waits for learners to attempt a task before intervening (54:-1)

The teacher uses questioning to ascertain what a learner understands, when they have not fully understood the demonstration (58:-1)

The teacher ensures that all learners know what they need to do to make progress $(62:-1)$ 
Table 11 Items sorted lower than others

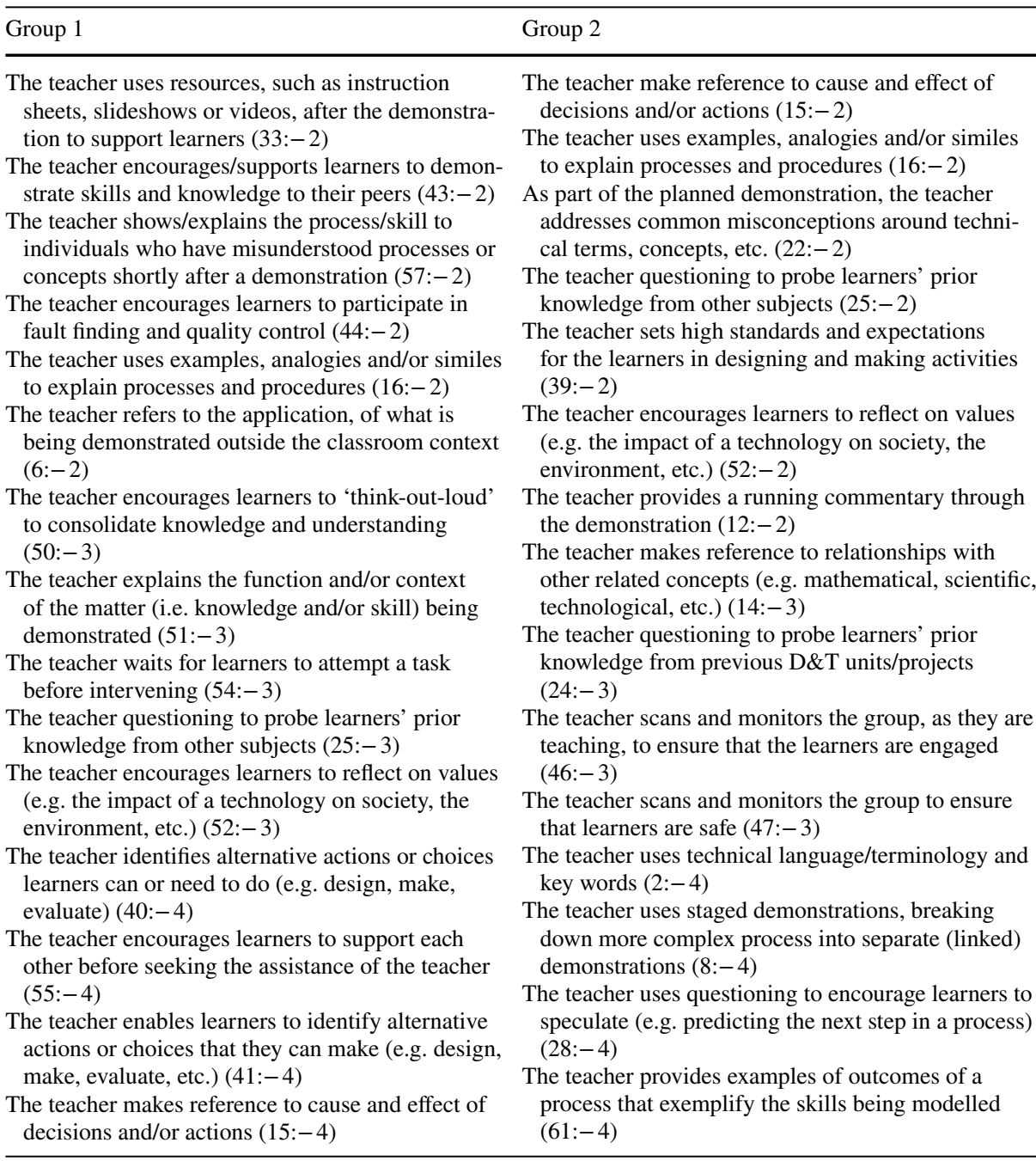

the teacher following the demonstration, to address misconceptions $(57:-2)$ or delaying teacher intervention until a learner has attempted a task (54:-3)

Similar themes that emerge in Groups 1 and 2, including: wider or contextual dialogue around implications of decisions and/or actions, reflection on values, such as technology in society and the environment, and explaining with the aid of examples, analogies and/or similes, reference to application of knowledge outside of the classroom or other learning resources.

Themes that emerge from Group 2 include making links with cross-curricular themes/ concepts $(14:-3)$. Other items in this category indicate that some activities may be viewed as relevant to specific situations, that arise with a demonstration, or lesson, such as addressing misconceptions (22:-2), questions to probe prior knowledge and understanding from within D\&T $(24:-3)$, other subjects $(25:-2)$ or to "encourage learners to 
speculate" (28:-4); and the used of staged demonstrations for "more complex process" $(8:-4)$. Whilst scanning the room for learners progress $(53: 2)$ was viewed as important, scanning and monitoring for engagement $(46:-3)$ and safety $(47:-3)$ was less so, which may indicate that they are encompassed or subsumed by a teacher focus on progression.

In line with ranking of other statements relating to the use of learning resources, the teacher educators in Group 1 assign lower value (Table 12) to the use of visual resources $(29:-5)$ or ICT $(20:-6)$ to support demonstrations, and making links to wider knowledge $(14:-5)$ and diagnostic processes (19:-5). Whilst an overview what is to be demonstrated is important (1:4), delivering this in one go is not $(9:-6)$.

For Group 2, the statements ranked in towards the bottom of the scale similar statements ranked in the top and middle of the range. However, this group rank questioning lower down the scale ( $c f$. Table 11). As such, no clear themes emerge for discussion from these data.

\section{Discussion}

The highest ranked responses for both groups support the notion that 'demonstration' was viewed by the participant, in the context of this study, as a structured process where the teacher breaks down learning into stages or steps. This reduces the cognitive load on learners, particularly young, novice or low socio-economic status learners who have not yet developed the mental schema to correctly interpret their observations (Kirschner et al. 2006). The ability to articulate concepts and processes effectively is essential for teaching effectiveness, and subject knowledge on its own is insufficient (Hattie 2009). There is a correlation between the highest ranked consensus statements ( $c f$. Tables 2,6) and the first four steps of Direct Instruction discussed above, which relate to learning intentions, success criteria, building engagement and the selection of appropriate methods.

Group 1 valued questioning to evaluate understanding (Hattie 2009; Adams and Engelmann 1996). Whereas, Group 2 valued encouraging learners to speculate (think-out-loud) to consolidate teaching (Martin 2016). Both groups valued the use of examples "to provide on what constitutes good work and how to do it" (Martin 2016, p. 13).

Table 12 Lowest ranked items

\begin{tabular}{|c|c|}
\hline Group 1 & Group 2 \\
\hline $\begin{array}{l}\text { The teacher models diagnostic processes, such as } \\
\text { using testing equipment to fault-find or the appli- } \\
\text { cation of scientific knowledge from an observa- } \\
\text { tion }(19:-5) \\
\text { The teacher uses visual resources, such as images, } \\
\text { photographs and diagrams, to enhance their dem- } \\
\text { onstrations ( } 29:-5) \\
\text { The teacher makes reference to relationships with } \\
\text { other related concepts (e.g. mathematical, scien- } \\
\text { tific, technological, etc.) }(14:-5) \\
\text { The teacher models/explains the whole process in } \\
\text { one demonstration }(9:-6) \\
\text { The teacher uses ICT to simulate or model process } \\
\text { or products }(20:-6)\end{array}$ & $\begin{array}{l}\text { The teacher refers to the application, of what is being } \\
\text { demonstrated outside the classroom context }(6:-5) \\
\text { The teacher adapts their approach and style of dem- } \\
\text { onstration to the learners, dependent on age, ability, } \\
\text { prior experience, etc. }(10:-5) \\
\text { The teacher gives clear verbal explanations of pro- } \\
\text { cesses and procedures }(11:-5) \\
\text { The teacher uses questioning to probe understanding } \\
\text { of concepts, process and procedures }(27: 6)\end{array}$ \\
\hline
\end{tabular}


Group 1 responses in Table 9 indicate a greater focus on teacher expertise, valuing technical language, defining what learners need to do to make progress and using questioning to evaluate understanding. Whilst Group 2 does not eschew these areas, the distinguishing responses emphasise their role in facilitating learner autonomy, through modelling diagnostic and fault-finding processes, encouraging learners to make choices when designing, making and evaluating, thinking out loud and the use of teaching assistants. However, both groups reflect approaches espoused by cognitive load theory, which are congruent with direct instruction approaches to learning.

The finding in this study broadly align with the model presented by McLain (2017; Figure 1), with "competence with subject knowledge" appearing most strongly with the participants, followed closely by "skilful classroom management". These are analogous with the themes of "teacher as expert" (Group 1) and "teacher as facilitator" (Group 2) in this study, with the prominence of the teacher's subject knowledge and classroom management changing places. Group 1 emphasising matters around expertise and knowledge over classroom management and differentiation, and vice versa for Group 2. It is important to note that both a views, and it is not the intention of the author to promote one view over the other, but rather to present the complex and multi layered nature of the demonstration.

Together, however, the combined emphasis on expertise and facilitation appears to reinforce the proposal that the demonstration is viewed, and possibly utilised, as a more restrictive pedagogical approach, on an expansive-restrictive continuum. This suggests the need for a more nuanced and flexible model than presented in Fig. 1, with teacher-led activity at the 'restrictive' end of the continuum and learner led at the 'expansive' (Fig. 3).

\section{Conclusion}

The role of the teacher is important at both ends of a restrictive-expansive continuum, and all points between. What changes is the level of intervention or scaffolding provided by the teacher. A tipping point between restrictive and expansive may be akin to a shift from 'mechanism' to complex overt response' in Simpson's taxonomy. The implications being, that a reflective teacher should consider the demonstration as a means-to-an-end. The end, or goal, being the autonomy and creative engagement of learners.

In identifying limitations for 'the demonstration', questions arise for D\&T practice; for beginning and experienced teachers, teacher educators and curriculum managers, around the selection and use of appropriate pedagogical methods for the intended purpose. For example:

- Is the purpose of a particular demonstration to learn how to mark out and cut a finger joint between two pieces of softwood? i.e. to focus on a specific practice or skill in D\&T;

Or

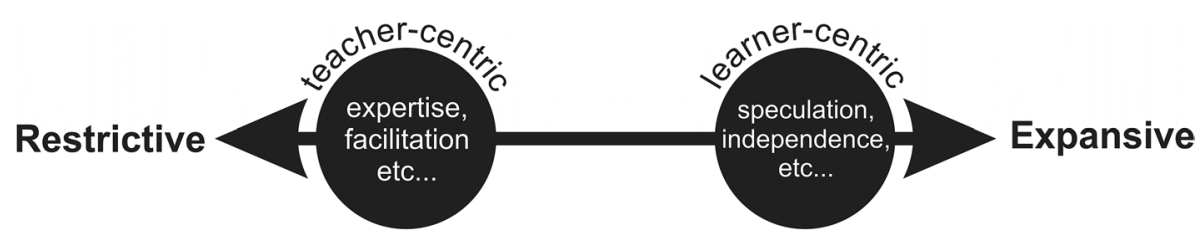

Fig. 3 expansive-restrictive model of demonstrating 
- Is it to select and use appropriate methods of permanently joining two pieces of material? i.e. to reflect on general principles in D\&T;

Questions also arise for D\&T educational researchers and policy makers. Such as:

- How do the signature pedagogies in D\&T reveal the subject's distinctive nature of the subject, and its role in the curriculum?

- What are signature pedagogies in D\&T, and does 'the demonstration' meet the criteria for inclusion?

In partial response to the second question above, given the similarities between the demonstration, as presented in this study, and the general pedagogy of direct instruction, the appellation 'signature' may not be appropriate in the strictest interpretation of the term. However, it does have an essential function in the pedagogical toolbox for D\&T educators, and as such, warrants further research.

Acknowledgements This paper presents a new and more in-depth analysis of data first presented by McLain (2016), as referenced in this article, at the Pupils' Attitudes Towards Technology (PATT) conference in August 2016, held in Utrecht, Netherlands.

Open Access This article is distributed under the terms of the Creative Commons Attribution 4.0 International License (http://creativecommons.org/licenses/by/4.0/), which permits unrestricted use, distribution, and reproduction in any medium, provided you give appropriate credit to the original author(s) and the source, provide a link to the Creative Commons license, and indicate if changes were made.

\section{References}

Adams, G., \& Engelmann, S. (1996). Research on direct instruction: 25 years beyond DISTAR. Seattle: Educational Achievement Systems.

Andersen, L. W., \& Krathwohl, D. R. (Eds.). (2001). A taxonomy for learning, teaching, and assessing: A revision of Bloom's taxonomy of educational objectives. New York: Addison Wesley Longman.

Bandura, A. (1977). Social learning theory. New Jersey: Prentice Hall.

Biesta, G. (2014). Pragmatising the curriculum: Bringing knowledge back into the curriculum conversation, but via pragmatism. The Curriculum Journal, 25(1), 29-49. https://doi.org/10.1080/09585 176.2013.874954.

Bloom, B. S., et al. (1956). Taxonomy of educational objectives: The classification of educational goalsHandbook 1, cognitive domain. New York: Longman Higher Education.

Brown, P. C., Roediger, H. L., III, \& McDaniel, M. A. (2014). Make it stick: The science of successful learning (1st ed.). London: The Belknap Press of Harvard University Press.

Collins, A., Brown, J. S., \& Holum, A. (1991). Cognitive apprenticeship: Making thinking visible. American Educator, 15(3), 38-46.

Dave, R. (1967). Psychomotor domain. Berlin: International Conference of Educational Testing.

DfE. (2010). The importance of teaching: The schools white paper 2010. London: Department for Education. Available at https://www.gov.uk/government/publications/the-importance-of-teaching-the-schoo 1s-white-paper-2010. Accessed 30 August 2019.

DfE. (2011). Teachers' standards: Guidance for school leaders, school staff and governing bodies. London: Department for Education. Available at https://www.gov.uk/government/publications/teachers-stand ards. Accessed 30 August 2019.

DfE. (2013). National curriculum in England: Design and technology programmes of study. London: Department for Education. Available at https://www.gov.uk/government/collections/national-curri culum. Accessed 30 August 2019. 
DfE. (2015). Design and technology GCSE subject content. London: Department for Education. Available at https://www.gov.uk/government/publications/gcse-design-and-technology. Accessed 30 August 2019.

Fuller, A., \& Unwin, L. (2003). Learning as apprentices in the contemporary UK workplace: Creating and managing expansive and restrictive learning environments. Journal of Education and Work, 16(4), 406-427.

Guba, E. G. (1981). Criteria for assessing the trustworthiness of naturalistic inquiries. Educational Communication and Technology, 29(2), 75-91.

Harrow, A. J. (1972). A taxonomy of the psychomotor domain. New York: David McKay Co.

Hattie, J. (2009). Visible learning: A synthesis of over 800 meta-analyses relating to achievement. London: Routledge.

Kimbell, R. (2018). Constructs of quality and the power of holism. In Proceedings of PATT36 research and practice in technology education: Perspectives on human capacity and development, June 18-21, 2018 (pp. 181-186). Athlone Institute of Technology, Co. Westmeath.

Kimbell, R., Stables, K., \& Green, R. (1996). Understanding practice in design and technology. Buckingham: Open University Press.

Kimbell, R., Stables, K., Wheeler, T., Wosniak, A., \& Kelly, V. (1991). The assessment of performance and design and technology. London: Schools Examination and Assessment Council.

Kirschner, P. A., Sweller, J., \& Clark, R. E. (2006). Why minimal guidance during instruction does not work: An analysis of the failure of constructivist, discovery, problem-based, experiential, and inquiry-based teaching. Educational Psychologist, 41(2), 75-86. https://doi.org/10.1207/s1532 6985ep4102_1.

Krathwohl, D. R., Bloom, B. S., \& Masia, B. B. (Eds.). (1964). Taxonomy of educational objectives: The classification of educational goals: Handbook 2-Affective domain. New York: David McKay.

Marranzo, R. J., \& Kendell, J. S. (2007). The new taxonomy of educational objectives (2nd ed.). London: Sage Publications Ltd.

Martin, A. J. (2016). Using Load Reduction Instruction (LRI) to boost motivation and engagement. Leicester: British Psychological Society.

McCormick, R. (1997). Conceptual and procedural knowledge. International Journal of Technology and Design Education, 7(1-2), 141-159.

McLain, M. (2016). Teacher educator perspectives on pedagogical modelling and explaining in design and technology: A Q Methodology study. In PATT32 conference, technology education for 21st century skills, August 23-26, 2016. Delft University of Technology and HU University of Applied Sciences.

McLain, M. (2017). Emerging perspectives on teacher modelling in design and technology. International Journal of Technology and Design Education, 28(4), 985-1000. https://doi.org/10.1007/s1079 8-017-9425-0.

McLain, M., Barlex, D., Bell, D., \& Hardy, A. (2015). Teacher perspectives on pedagogical modelling and explaining in design \& technology: A Q Methodology study. In M. Chatoney (Ed.), Plurality and complementarity of approaches in design and technology education, April 2015, Marseille, France. Available at: https://hal.archives-ouvertes.fr/hal-01161553. Accessed 30 August 2019.

McLain, M., Bell, D., \& Pratt, A. (2013). Show-how know-how (part 1): Theory and practice for demonstrating in design and technology. D\&T practice, 3/2013. Wellesbourne: Design and Technology Association.

McLellan, R., \& Nicholl, B. (2011). "If I was going to design a chair, the last thing I would look at is a chair": Product analysis and the causes of fixation in students' design work 11-16 years. International Journal of Technology and Design Education, 22(1), 71-92.

Milne, C., \& Otieno, T. (2007). Understanding engagement: Science demonstrations and emotional energy. Science Education. https://doi.org/10.1002/sce.20203.

Mincu, M. E. (2015). Teacher quality and school improvement: What is the role of research? Oxford Review of Education, 41(2), 253-269. https://doi.org/10.1080/03054985.2015.1023013.

Morrison-Love, D. (2017). Towards a transformative epistemology of technology education. Journal of Philosophy of Education, 51(1), 23-37.

Mosston, M., \& Ashworth, S. (2002). Teaching physical education (5th ed.). San Francisco: Pearson Education Inc.

Petrina, S. (2007). Advanced teaching methods for the technology classroom. London: Information Science Publishing.

Pruneddu, A. (2014). QSortWare [Online software]. Available at http://www.qsortouch.com. Accessed 30 August 2019. 
Reynolds, D., Sammons, P., De Fraine, B., Van Damme, J., Townsend, T., Teddlie, C., et al. (2014). Educational effectiveness research (EER): A state-of-the-art review. School Effectiveness and School Improvement, 25, 197-230.

Rowe, K. (2006). Effective teaching practices for students with and without learning difficulties: Constructivism as a legitimate theory of learning AND of teaching? Student Learning Processes. Available at http://research.acer.edu.au/learning_processes/10. Accessed 30 August 2019.

Ryle, G. (1949, 1990). The concept of mind. London: Penguin Books Ltd.

Schmolck, P. (2014). PQPethod (version 2.35) [software]. Available at http://schmolck.userweb.mwn.de/ qmethod/index.htm. Accessed 30 August 2019.

Shulman, L. S. (1986). Those who understand: Knowledge growth in teaching. Educational Research Review, 57(1), 4-14.

Shulman, L. S. (2005). Signature pedagogies in the professions. Daedalus, 134(3), 52-59.

Simpson, E. J. (1972). The classification of educational objectives in the psychomotor domain. Washington, DC: Gryphon House.

Stephenson, W. (1935). Technique of factor analysis. Nature, 136, 297.

Sternberg, R. J. (2009). Forward. In S. Tobias \& T. M. Duffy (Eds.), Constructivist instruction: Success or failure?. Abingdon: Routledge.

Vygotsky, L. S. (1978). Mind in society. Cambridge: Harvard University Press.

Watts, S., \& Stenner, P. (2012). Doing Q methodological research: Theory, method and interpretation. London: Sage Publications Ltd.

Wood, D., Bruner, J., \& Ross, G. (1976). The role of tutoring in problem solving. Journal of Child Psychology and Psychiatry and Allied Disciplines, 17, 89-100. https://doi.org/10.1111/j.1469-7610.1976. tb00381.x.

Publisher's Note Springer Nature remains neutral with regard to jurisdictional claims in published maps and institutional affiliations. 